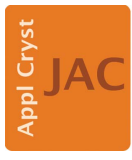

JOURNAL OF APPLIED CRYSTALLOGRAPHY

ISSN 1600-5767

Keywords: editorial; Journal of Applied Crystallography.

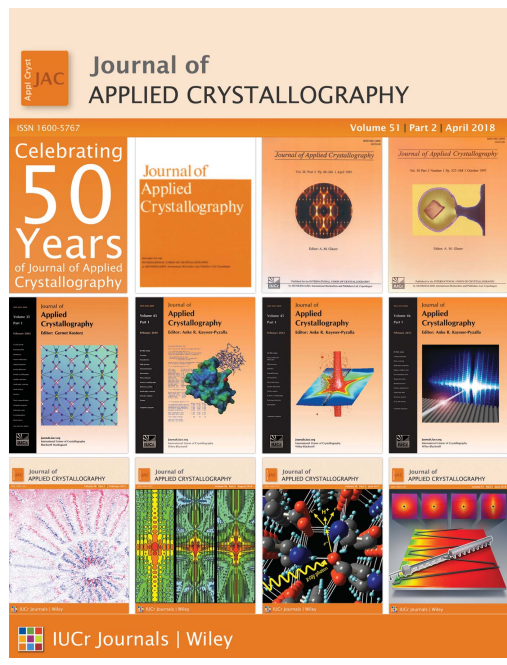

(C) 2018 International Union of Crystallography

\section{Journal of Applied Crystallography: the first 50 years and beyond}

\author{
Andrew J. Allen, ${ }^{\mathrm{a} *}$ Janos Hajdu ${ }^{\mathrm{b}, \mathrm{c} *}$ and Garry J. McIntyre ${ }^{\mathrm{d} *}$ \\ aMaterials Measurement Science Division, National Institute of Standards and Technology, 100 Bureau Drive, \\ Gaithersburg, MD 20899, USA, 'baboratory of Molecular Biophysics, Department of Cell and Molecular Biology, \\ Uppsala University, Husargatan 3 (Box 596), SE-751 24 Uppsala, Sweden, 'The European Extreme Light Infrastructure, \\ Institute of Physics, AS CR, Na Slovance 2, Prague 18221 8, Czech Republic, and Australian Nuclear Science and \\ Technology Organisation, New Illawarra Road, Lucas Heights NSW 2234, Australia. *Correspondence e-mail: \\ andrew.allen@nist.gov, janos@xray.bmc.uu.se, garry.mcintyre@ansto.gov.au
}

The first issue of Journal of Applied Crystallography appeared in April 1968. ${ }^{\mathbf{1}}$ So, with this issue we celebrate its 50th birthday. We should start by expressing our appreciation for all the readers, authors, reviewers, editors and technical staff who have made the journal what it has become over the past 50 years. The first Editor of Journal of Applied Crystallography was the pioneer of small-angle scattering, André Guinier, who guided the journal through its first two volumes in 1968 and 1969, after which he stood down on being elected IUCr President. André Guinier was succeeded by Ray Young who served as Editor from 1970 to 1978, Michael Hart from 1978 to 1984, Michel Schlenker from 1984 to 1990, Michael Glazer from 1990 to 1999, Gernot Kostorz from 1999 to 2007 and Anke Kaysser-Pyzalla from 2007 to 2017. Anke Kaysser-Pyzalla was joined by two of us, Janos Hajdu and Andrew Allen, in 2014, and she was succeeded by our other current Main Editor, Garry McIntyre, in 2017.

Although the name suggests a focus on crystallography, Journal of Applied Crystallography has served a broad interdisciplinary readership ever since its conception, and the very first paper published was a paper on electron microscopy [Heidenreich, Hess \& Ban, A test object and criteria for high resolution electron microscopy, J. Appl. Cryst. (1968), 1, 1-19]. The first issue was just 60 pages, containing Research Papers, Notes and News, and a Book Review. The first Short Communications appeared in the second issue, as well as a section on Forthcoming Meetings and Short Courses. By the end of the first volume, Laboratory Notes also began to appear, and in the August 1969 issue the first Computer Program paper was published; a Teaching and Education section appeared in the 1990s. Meanwhile, from the third volume onwards, the size of each issue began to expand, and Journal of Applied Crystallography developed its reputation as a reliable forum for rigorously reviewed papers across the whole breadth of applied crystallography, with a strong presence of interdisciplinary research combining crystallographic methods with other measurements. Building on the legacy of its founding Editor, another occasional feature that developed from 1974 onwards was a conference proceedings issue associated with the triennial small-angle scattering conferences.

For the first 30 years or so of the journal's life, every paper was submitted to Journal of Applied Crystallography as hard copy, and letters were sent in the mail (air mail for international correspondence) back and forth to authors and reviewers and the Editorial Office. One of us (AJA) still has the ink press and 'Not for Disclosure' stamp to use on review materials he was given on first becoming a Co-editor back in 2002. It was a different age for science journal publication! Gradually, slow mail was replaced by email, and finally by the web-based review system we have today. From 2014, the printed version of the journal disappeared and Journal of Applied Crystallography, in common with all IUCr journals, became online only.

To remain competitive in the modern world of science publication, our review times have decreased, our rejection rate has had to increase and we have stopped publishing traditional conference proceedings issues. However, we do have special issues, some of which are associated with conferences, for the publication of select numbers of highquality papers - provided the regular review standards are maintained. We also encourage Features, Lead Articles and Commentaries when these are appropriate and, increasingly, authors are opting to make their papers open access. Despite some 
Table 1

Top ten cited papers on the basis of Web of Science data.

1. PROCHECK: a program to check the stereochemical quality of protein structures. Laskowski, R. A., Macarthur, M. W., Moss, D. S. \& Thornton, J. M. (1993). J. Appl. Cryst. 26, 283-291. https://doi.org/10.1107/S0021889892009944. (Most cited paper from our third decade: 1988-1997.)

2. MOLSCRIPT: a program to produce both detailed and schematic plots of protein structures. Kraulis, P. J. (1991). J. Appl. Cryst. 24, 946-950. https://doi.org/ 10.1107/S0021889891004399.

3. Single-crystal structure validation with the program PLATON. Spek, A. L. (2003). J. Appl. Cryst. 36, 7-13. https://doi.org/10.1107/S0021889802022112. (Most cited paper from our fourth decade: 1998-2007.)

4. A profile refinement method for nuclear and magnetic structures. Rietveld, H. M. (1969). J. Appl. Cryst. 2, 65-71. https://doi.org/10.1107/S0021889869006558. (Most cited paper from our first decade: 1968-1977.)

5. SIR97: a new tool for crystal structure determination and refinement. Altomare, A., Burla, M. C., Camalli, M., Cascarano, G. L., Giacovazzo, C., Guagliardi, A., Moliterni, A. G. G., Polidori, G. \& Spagna, R. (1999). J. Appl. Cryst. 32, 115-119. https://doi.org/10.1107/S0021889898007717.

6. Phaser crystallographic software. McCoy, A. J., Grosse-Kunstleve, R. W., Adams, P. D., Winn, M. D., Storoni, L. C. \& Read, R. J. (2007). J. Appl. Cryst. 40, 658674. https://doi.org/10.1107/S0021889807021206.

7. OLEX2: a complete structure solution, refinement and analysis program. Dolomanov, O. V., Bourhis, L. J., Gildea, R. J., Howard, J. A. K., Puschmann, H. (2009). J. Appl. Cryst. 42, 339-341. https://doi.org/10.1107/S0021889808042726. (Most cited paper from our fifth decade: 2008-2017.)

8. Completion and refinement of crystal structures with SIR92. Altomare, A., Cascarano, G., Giacovazzo, C. \& Guagliardi, A. (1993). J. Appl. Cryst. 6, 343-350. https://doi.org/10.1107/S0021889892010331.

9. EXPGUI, a graphical user interface for GSAS. Toby, B. H. (2001). J. Appl. Cryst. 34, 210-213. https://doi.org/10.1107/S0021889801002242.

10. WinGX and ORTEP for Windows: an update. Farrugia, L. J. (2012). J. Appl. Cryst. 45, 849-854. https://doi.org/10.1107/S0021889812029111.

For completeness, we should add the top cited paper from our second decade: 1978-1987. A nitrogen-gas-stream cryostat for general X-ray-diffraction studies. Cosier, J \& Glazer, A. M. (1986). J. Appl. Cryst. 19, 105-107. https://doi.org/10.1107/S0021889886089835.

fluctuations in the number of journal pages published per year (i.e. per volume), this has been approximately 2000 pages a year for the past few years. Through the hard work of all our editors and editorial staff, Journal of Applied Crystallography continues to be recognized as a place to publish significant and rigorously reviewed research featuring applied crystallography and crystallography applied in an interdisciplinary setting, as well as studies on noncrystalline materials. The underlying impact factor appears to be stable at around 2.5, but with substantial positive excursions associated with particularly valuable (and highly cited) Computer Program software papers, and sometimes instrumental facility papers we strongly encourage such submissions! Our mix of published papers continues to include work associated with high-brilliance synchrotron and free-electron laser X-ray sources, despite many other avenues (both IUCr and non-IUCr) being available for reporting such research. We retain a strong presence in neutron scattering applications, and we continue to encourage industrial applications of crystallography. Finally, our founding Editor, André Guinier, would be very pleased to see that the prominence of small-angle scattering, the field he founded, has not diminished in these pages over the years.

Table 1 lists the top ten cited papers to have appeared in Journal of Applied Crystallography over its first 50 years.

Looking to the future, there are obviously many challenges ahead for scientific publishing. IUCr journals, including Journal of Applied Crystallography, will continually look for ways to be more competitive. For example, we foresee an increasing requirement for authors to tune the title, abstract, and first one or two paragraphs in the Introduction of their paper to ensure that an interested reader quickly understands why the paper may be worth reading. Obviously, in most cases, the Conclusions also need to bring closure in that they show how the paper has provided a response to the points raised at the start. In the coming months, we will be asking our editors and reviewers alike to pay more attention to this sort of issue. Authors should expect to be asked to make pre-review revisions to address these concerns if the editor perceives a problem. With changing publication models and requirements, we encourage authors to archive their data in retrievable form, using data banks, their institution's capabilities or those available with the IUCr. We also encourage all authors to consider the open-access option for their papers, even when not mandated by their funding agencies. Our citation data indicate that, for articles published in the journal since 2014, the average number of citations per open-access article is 7.65 , significantly higher than the average of 4.49 citations for non-open-access articles. A small part of the revenue from open-access publication and from the new IUCr Associates Programme goes towards supporting the work of the IUCr.

We should close as we started by thanking everyone involved with Journal of Applied Crystallography, both past and present, for all their hard work to make journal's first 50 years so successful. We look forward to working with the Journal of Applied Crystallography community to make the next 50 years even better.

\footnotetext{
${ }^{1}$ The Executive Committee of the International Union of Crystallography in September 1967 made a decision 'To launch a new journal called Journal of Applied Crystallography in April 1968. This journal would be concerned with methods, apparatus, problems and discoveries in applied crystallography. The Sixth General Assembly in 1963 had already approved of the publication of a Journal of Applied Crystallography.' [Acta Cryst. (1968). A24, 705-714.]
} 